\title{
Study on Yan Fu's Translation from the Perspective of Modernity
}

\author{
Xixiang Ke
}

Wuhan Textile University, Wuhan, China 430070

1753270552@qq.com

Keywords: Yan Fu; Modernity; Interpretation; Paradox

\begin{abstract}
Yan $\mathrm{Fu}$ who is a prolific and great translator in late Qing dynasty builds Chinese enlightenment thoughts and new culture by the translation of western bourgeois culture, many works concerning social science included. This paper is to analyze Yan Fu's translation from the perspective of modernity. The role translation literature plays on the process of Chinese modernity is also discussed afterwards.
\end{abstract}

\section{Introduction}

Yan $\mathrm{Fu}$ is a great translator and thinker in Chinese modern history who builds Chinese enlightenment thoughts and new culture by the translation of western bourgeois culture. Yan Fu's learning experiences expose himself to the advanced western political and legal system. And his understanding of the western philosophy, sociology, economics and other humanities and social sciences has made him one of the few Chinese people to explore western culture.

In early twentieth century, Yan Fu expressed his ideas to reconstruct a new Chinese culture via seeking similarities between Chinese culture and Western culture concerning their past, present and future with the purpose of the salvation and independence and prosperity of China.

Yan Fu's ideas of creating new culture came from the stimulus of China's failure in the Sino Japanese war. Conservatives did not intend to reform and intellectuals were still arrogant. In order to awaken numb people, he decided to translate Huxley' theory of evolution with a strong evolutionary thought.

Yan $\mathrm{Fu}$ adopted the classic Chinese of Tongcheng style. Along with creative domestication and note technique, Yan Fu translated the Huxley's theory- survival of the fittest, which shook Chinese ideological and cultural circles. Yan Fu introduced advanced western bourgeois culture to China via the translation of a series of western works which laid a new view of the universe for creating Chinese new culture, and deeply influenced generations of Chinese including Lu Xun, Mao Zedong, then new culture becomes a powerful ideological weapon to observe society and world.

\section{A Transitional Character from the "pre-modern" to "modern" Thought}

As mentioned earlier, the term "pre- modern" refers to a state of stillness, circulation and tradition. "Modern" is a new sense of time, whose rise is to cut the relevance to the past. The relationship between the future and the past are not equal, the future being a current problem.

As Osborne [1] said, the modern awareness of time, a new product, is a time of culture. The temporality or the politics of time is the core of culture. From the social perspective, modernity refers to the traditional (post-traditional) and middle (post-medieval) era[2], and it is the process for society to go from the feudal agricultural civilization to capitalism, industrialization, rationalism, nation-state and its corresponding system and monitoring systems. Its symbol is the formation, growth and development of the following things: modern philosophy (especially the universalism of European center, sociology, political thought, modern culture and art, modern science, technology and invention, modern industry and war, etc. 


\section{Yan Fu's Paradox: The Modern Nature of Material Selection and the Anti-modern of Translation Language}

Material selection of translation involves economics, politics, law, ideology and culture. Each selection comes after careful consideration. Whatever he thinks is suitable for China and whatever China needs or lacks at the moment, he would translate into Chinese in order to arouse people's consciousness of modernity and interest to learn new science and new ideas. His selections are based on need, therefore each selection is made with profound intention.

Yan Fu would refer to whatever book is relevant to the original. Any associated with the inherent culture of China and the original idea of the book translated are referred to by him.

In a word, his choice of translation is based on the conditions at that time. Yan Fu, however, is not too observant of conventional standards for the transmission of modern culture in the process of translation. He did not faithfully transfer the original, but made changes according to his own needs.

In the interpretation of modernity, Yan Fu grasps the degree. He does not copy western modernity, for example, Yan focuses on translating evolution part in translating the theory of evolution and ethics [3]. The book entitled freedom is changed into "群己权界论". These involve the degree of modernity. His transition partly introduces the content of western modernity, which is reflected in the early, middle and late translation works of Yan Fu.

The relationship between Yan Fu and modernity is positive, direct, political and uncontroversial. Yan Fu's translation is all about economic and political science. Yan Fu's paradox is that he knows what is modern. This is reflected by his selection of western modern ideas. Besides, he realizes what language is modern.

However, the use of classical Tongcheng Chinese under that circumstance is undoubtedly the best translation language. On the surface, it seems contrary to modern translation language, but in the long run, that is the best translation language adopted to suit the situation at that time. In order to alert the literati and officialdom of the time, Yan employed the Tongcheng language which is easy to be accepted by the literati and officialdom to translate western writings. Yan Fu believes that China's modernity, first of all should convince cultured class then common people.

The process of Chinese modernity needs a process, which should be handled delicately, otherwise it will be counterproductive. It is Yan Fu's consideration that the spread of Western modernity in China is extremely successful. The anti-modernization of translation language is to promote the spread of Western modernity in China and to promote the modern transformation of Chinese cultural thought. The translation language is not seemingly backward and anti-modern, but actually a wise choice.

\section{Role of Yan Fu and Translation Literature on the Chinese Modernity Process}

Hegel once argued in aesthetics that certain content determines a form suitable for it[4]. He believes that the defects of form come from the defects of content. The content employed to promote people's ideological change determines its present form, an anti-modern translation language. The use of translation style derives from the particular need and its content. These are content form of the source language presentation. Ralph Fawkes in his novel pointed out that form is from content and conform to content; although content comes first, but form reacts to content, never being in the passive position. -Eagleton. The essence of anti-modern translation language form is the same with the content, and the form reacts to the content at the same time thus spread content, having a profound effect in history.

Each writer or translator, living in a certain society, react to the whole history according to his own special position and views and make the reaction concrete in its own language. Yan Fu who lives in the late Qing Dynasty, according to his own special position reacted to the late Qing Dynasty situation -advocate self preservation by means of literary translation to enlighten people, encourage people and modernize people. He translates advanced western culture with his own special language - the old Chinese with Tongcheng style. Through the translation of literary works, Chinese observed and understood the world, understanding the translation literature is to understand 
the whole process of the western society. The appearance of translation literature reflects the needs of China in that era, which is an inevitable manifestation of that era. Yan Fu adapted to the needs of the times, thus promote the development of times. The situation in the late Qing Dynasty creates a great translator and thinker like Yan Fu.

It is necessary to combine the social environment at that time with Yan Fu's view of translation with the purpose of understanding Yan Fu's translation works. However, the selection of the subject matter and the content of the translated works are both in accordance with the needs and the specific purpose of translation. So he also says that his early translation is purpose-oriented. Yan Fu put forward his three translation standards-faithfulness, fluency and elegance[5], while his own translation is not strictly in accordance with this standard, which is often criticized by translators after him.

Yan Fu's translation work is really not faithful to the original?

Then it is possible to use Foucault and Said's views to explain the specific translation of Yan Fu. Foucault and Said think that translation of humanities and social sciences can't be measured by the standard of fidelity [6]. Their translations are carried out under the influence of specific rights and interpretation of certain frame of knowledge. From this point of view, the criterion of faithfulness is not the criterion of epistemology, but the standard of political science. The content of Yan Fu's translation belongs to the humanities and Social Sciences, and the selection of translation materials and translation activities are based on the needs of politics. Foucault believed in the existence of truth, assuming that there are many kinds of truths, and different forms of truth interpretation.

Foucault's views can be used to interpret the faithfulness of translation principles. We believe in the existence of faithfulness and hold the assumption that there are a variety of faithfulness and different forms of fidelity [7]. Then from this point of view, Yan Fu's infidelity once denounced should be another form of faithful expression, or an alternative loyalty. The postcolonial and feminist translators believe that the faithfulness of translation is not faithful to the original text, but to a translation program. It might be possible to explain Yan Fu's translation, which is a kind of unfaithful faithfulness based on a specific need. The theory of evolution, seemingly unfaithful, but a faithfulness based on the needs of the times and modernity. Yan Fu gives the original a new vitality, which was particular interpreted by particular readers - the Chinese people. Thus China's close contact with the modern ideas is possible.

Translation is also a kind of discourse making, which Yan Fu made full use of in translation, as he divert, add and delete the original to meet the need of conveying modern ideas. Compared with the original text, the translation (target text) is neither true nor false or both faithful and unfaithful. The target text comes from the source text, and deviated from the original, which is fully displayed by Yan Fu. Maybe this is also the embodiment of Yan Fu's the subjectivity of the translator, just as Roland Barthes states[8], the author is dead, the translator's initiative is developed, then their translation is based on the purpose of translation. Thus readers are born and continue to spread the life of the original. Yan Fu's faithfulness is faithful to his own original intention of translation! How can he be criticized just for being unfaithful?

Yan Fu's faithfulness is to serve the practical needs of China -to help people strengthen themselves - ideological basis for self-independence. Yan Fu does not completely copy the western modernity, with embezzlement and revision combined - such as social evolution and survival of the fittest, deliberately downplaying natural evolution theory. From this perspective, Yan Fu's translation of Western works is also a process of acceptance, and this acceptance is also a choice, the choice of translation content and focus. The acceptance experienced abridgement, value transformation process. simplicity, but also being complicated. Acceptance, being independent, has the ability to innovate rather than blindly rely on the original copy.

Yan Fu's translation has additions, comments, a fusion of Chinese and Western interpretation. An anti- modern translation language makes the translation well-received in foreign countries like China, causing great ideological revolution. Yan Fu, only chooses the part of Spencer's theory of evolution to translate, which seems to be a simplified version. And this simplified version becomes complex in foreign countries, getting a different experience and communication. This is Yan Fu's 
innovation in the process of acceptance.

Derrida believes that the development of translation is often beyond the control of the original and beyond translator's intention thus achieving an independent life [9]. Yan Fu overturned the authority of Western writings by reconstructing the so-called post-colonial subject or semi-colonial subject by means of choice, comment and transformation.

What Yan $\mathrm{Fu}$ does according to contemporary western critical discourse seems to meet the Spivak's so-called strategic essentialism strategy and its own post-colonial subject seems to be constructed at this level. He deconstructed the original centrality, and constantly consult and communicate with the original, emphasizing the subjective consciousness of the colonized and translator.

The colonists have to get rid of the hegemony of the colonists to reproduce the text and to write their own history as the main body, carry out the literary production activities of decolonization with the new thinking and strategy [10]. This paradigm shift is reflected in Yan Fu's attitude towards mainstream English.

\section{Summary}

In short, whether the modern nature of the translation content or of the anti-modern translation language, or its alternative translation criteria - the standard of political translation, if we can think so, reveals the translator Yan Fu's subjectivity. All this is to promote the spread and acceptance of Western modernity in China in order that China at that time can enter modernization pattern, trying to be in the track of world development rather than passively falling behind. Active pursuit of modernity rather than passive encounter of modern are what Yan Fu expects. Modernity is always an unfinished business and one goal we always want to achieve. We want to create the modernity of the world, and future modernity is no longer just a modern system and structure of mind as a symbol, but the common development of human harmony as a symbol, which is our goal of all mankind. The modernity of the world, east and west included, China naturally should contribute to it.

\section{Acknowledgement}

This work was financially supported by education department of Hubei Province (NO.16Y066).

\section{References:}

[1] Shan Jigang, Philosophical Aspects of Translation, China Social Sciences Press, 2007, pp. 221225.

[2] Zhao Xifang, Translation Modernity, Nankai University Press, 2012, pp. 136-139.

[3] Huxley, Song Qilin, Evolution and Ethnics, first ed., Beijing University Press, 2010.

[4] Peng Junping, On Hegel Publishing House of China, 2014, pp.41-42.

[5] Wang Shi, Selection of Yan Fu's Works, first ed., Publishing House of China, 1986, pp. 1331.

[6] Edward W. Said, Culture and Imperialism, Published by Vintage 1994.

[7] James L. Hevia, English Lessons, the pedagogy of imperialism in nineteenth-century China, Duke University Press, 2003.

[8] Fei Xiaoping, The Politics of Translation, China Social Sciences Publishing House, 2005.

[9] Zhu Liyuan, Contemporary Western Literary Theories. Huadong Normal University Press, 2005, pp.265-270.

[10] Sun Huijun, Universe and Difference, Shanghai Translating Press, 2005, pp. 85-95. 